\title{
Dois sepultamentos, um monumento: a construção da memória do médico e missionário George William Butler (1915-1944)
}

\author{
Rogério de Carvalho Veras*
}

\section{Resumo}

Este é um estudo sobre a memória de George William Butler (1853-1919), médico e missionário protestante que viveu no Nordeste brasileiro entre 1883 e 1919 . O objetivo deste artigo é propor uma interpretação da construção da memória de George Butler a partir de um sepultamento de restos mortais, realizado em 1915, pelo médicomissionário, no interior da Igreja Presbiteriana de Canhotinho-PE. Relaciono esse rito dirigido por Butler à construção de seu próprio lugar de memória junto àquele grupo religioso. Lugar esse consolidado com a edificação em 1944, 25 anos depois de sua morte, do "Mausoléu do Dr. Butler", no mesmo local do seu túmulo, ao lado do templo da igreja. Por essa época, as duas sepulturas se fundiram em um mesmo monumento, transmitindo um sentido normativo sobre os valores, os modelos e as práticas do grupo religioso protestante no interior nordestino.

Palavras-chave: Memória. Protestantismo. Rito. Monumento. George William Butler.

\section{Two sepultaments, one monument: the construction of the memory of physician and missionary George William Butler (1915-1944)}

\section{Abstract}

This is a study of the memory of George William Butler (1853-1919), a physician and Protestant missionary who lived in the Brazilian Northeast from 1883 to 1919. The purpose of this article is to propose an interpretation of the construction of George Butler's memory considering a burial of mortal remains, carried out in 1915, by the doctor-missionary, inside the Presbyterian Church of Canhotinho-PE. Search to relate this rite directed by Butler to the construction of his own place of memory next to that religious group. This place was consolidated in 1944, with the erecting "Dr. Butler's Mausoleum" in the same place of his tomb, next to the church temple, 25 years after his death. In this time, the two graves merged in a same monument, transmitting

* Doutor em História pela Universidade Estadual Paulista (UNESP/Assis-SP) e professor da Universidade Federal do Maranhão (UFMA/Imperatriz-MA). 
a normative sense about the values, the models and the practices of the protestant religious group in the northeastern interior.

Keywords: Memory. Protestantism. Rite. Monument. George William Butler.

\section{Dos sepultos, un monumento: la construcción de la memoria del médico y misionero George William Butler (1915-1944)}

\section{Resumen}

Este es un estudio sobre la memoria de George William Butler (1853-1919), médico y misionero protestante que vivió en el Nordeste brasileño entre 1883 y 1919. El objetivo de este artículo es proponer una interpretación de la construcción de la memoria de George Butler a partir de un entierro de restos mortales, realizado en 1915, por el médico-misionero, en el interior de la Iglesia Presbiteriana de Canhotinho-PE. Relacionar este rito dirigido por Butler a la construcción de su propio lugar de memoria junto a aquel grupo religioso. Lugar que se consolidó con la construcción en 1944, 25 años después de su muerte, del "Mausoleo del Dr. Butler", en el mismo lugar de su tumba, al lado del templo de la iglesia. Por esta época, las dos sepulturas se fusionaron en un mismo monumento, transmitiendo un sentido normativo sobre los valores, los modelos y las prácticas del grupo religioso protestante en el interior nordestino.

Palabras clave: Memoria. Protestantismo. Rito. Monumento. George William Butler.

\section{Introdução}

Natural de Roswell, na Geórgia, sul dos Estados Unidos, George William Butler (1853-1919) dedicou a maior parte de sua vida a ser médico e missionário protestante no Nordeste brasileiro, onde viveu entre os anos de 1883 a 1919. Ele residiu em São Luís-MA, Recife-PE e Garanhuns-PE, antes de se estabelecer por 22 anos em Canhotinho, também no interior pernambucano. Ali construiu um templo protestante, uma escola e um hospital atraindo milhares de sertanejos devido à fama de milagreiro.

Hoje, ao lado do templo presbiteriano de Canhotinho, há um monumento conhecido como "Mausoléu do Dr. Butler". É assim que é apresentado aos visitantes, além de divulgado nos livros e artigos de história da Igreja Presbiteriana, em documentários institucionais, páginas eletrônicas e pelos biógrafos de George Butler. ${ }^{1}$ Esse "Mausoléu” causou-me espanto

São três as biografias sobre George Butler, A Bíblia e o Bisturi, de Edijéce Martins (em três edições: 1976, 1987, 2007), O Padre Cícero Protestante, de Rodrigues e Clementino (2015) e uma dissertação de mestrado de autoria do conhecido historiador do protestantismo David Gueiros Vieira, intitulada, A Historical Study of the Missionary Work of Dr. George W. Butler and an Analysis of his Infuence on Brazil, defendida em 1960 na Universidade de Richmond nos Estados Unidos. Outras obras de historiadores do presbiterianismo como Caleb Soares (2010), Célio Siqueira (1996), José Roberto de Sousa (2015) sempre se 
e certo estranhamento, o percebi como um monumento-enigma: como foi possível uma sepultura ser posta ao lado de uma igreja protestante e o morto ser reverenciado e exaltado como um herói, tendo seu nome vinculado àquela igreja?

Segui, então, a sugestão de Robert Darnton de fazer da minha "sensação de estranhamento o ponto de partida para captar a condição do outro" (BURKE, 1997, p. 3). Esse monumento representou a minha "incapacidade de entender a piada" (DARNTON, 1986, p. 106) e foi o riso que fazia sentido aos indivíduos de uma cultura distanciada no tempo, mas que perdeu o sentido na minha condição histórica. Esse foi o gatilho para “explorar certas diferenças entre o presente e o passado" (BURKE, 1997, p. 3) e procurar reconstituir as lógicas da produção desse monumento.

Fui a Canhotinho, visitei a igreja e o "Mausoléu do Dr. Butler" (Figura 1). O que já me era estranho tornou-se ainda mais intrigante ao saber que George Butler não descansa ali sozinho. Com o médico e missionário foram postos os restos mortais do seu filho, o também médico Humphrey Butler, morto apenas três anos após o pai, mas a sua presença ali é bem pouco aludida. Outra presença é mais lembrada, a dos restos de Manuel Correia Vilella, ou simplesmente Né Vilella. O fato de Né Vilella descansar na sepultura da família Butler é justificado pelos fiéis e historiadores presbiterianos em razão daquele ter morrido, em 1898, num atentado cujo alvo seria George Butler.

Em julho de 1915, portanto dezessete anos após a morte de Né Vilella, foi o próprio George Butler quem se encarregou de trazer a sua ossada para o interior da igreja. Os restos mortais foram transportados em uma urna e colocados durante uma cerimônia de reinauguração do templo, na base do púlpito e sob uma placa. Esse rito de translado e (re)sepultamento é narrado pelos historiadores presbiterianos (MARTINS, 2007; FERREIRA,

referem ao mausoléu onde está enterrado George Butler. Há também páginas eletrônicas do presbiterianismo local (Disponível em: <https://oagrestepresbiteriano.blogspot. com/2013/06/historia-da-igreja-presbiteriana-do.html>. Acesso em 10 jul. 2015), apresentando a história da Igreja Presbiteriana de Canhotinho fundamentalmente ligada a George Butler, destacando a presença do seu mausoléu ao lado da igreja, além de um documentário da Igreja Presbiteriana do Brasil, em celebração ao seu $150^{\circ}$. aniversário, intitulado Igreja Presbiteriana, 150 anos evangelizando o Brasil (Disponível em: https://www. youtube.com/watch?v=bjmbdP9_z3o. Acesso em 6 fev. 2016), que ao tratar da história do presbiterianismo no Nordeste do Brasil (a partir do minuto 39:00 até ao 47:50) dar maior ênfase à história de George Butler, utilizando imagens da igreja e do mausoléu. 
Figura 1: Mausoléu do Dr. Butler.

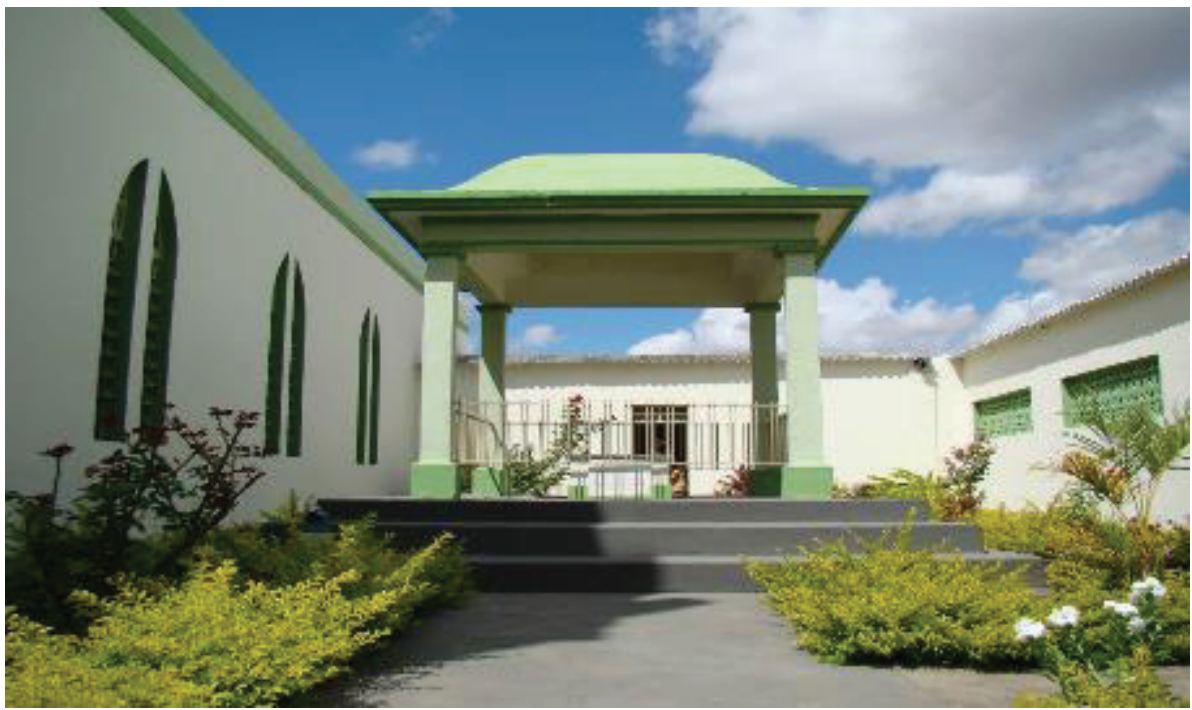

Fonte: Foto de Elio Rocha, extraído de: www.panoramio.com/photo/19064822\#c87063607

1959; LESSA 1938) e nas fontes históricas eclesiásticas ${ }^{2}$ em tom de louvor ao médico e missionário, descrevendo a emoção que tomou conta dos participantes e do próprio Butler ao homenagear o amigo por ter "morrido em seu lugar".

Tive acesso a esses documentos, jornais e revistas presbiterianos por meio de incursões realizadas em arquivos de instituições que outros pesquisadores me indicaram no percurso da pesquisa, como: o LIBER (Laboratório de Tecnologia da Informação da Universidade Federal de Pernambuco), que guarda um acervo do jornal presbiteriano Norte Evangélico, publicado em Garanhuns-PE nas primeiras décadas do século XX; o Arquivo Presbiteriano de São Paulo, guardião de vários periódicos e documentos a respeito do presbiterianismo brasileiro; também estive no arquivo da Presbyterian Historical Society em Filadélfia-EUA, onde encontrei diversas fontes primárias, cartas e fotografias do missionário pesquisado, de sua esposa e de pessoas próximas a eles, bem como, todas as edições das revistas missionárias presbiterianas The Missionary e The Missionary Survey. Por fim, visitei as cidades

\footnotetext{
2 As principais fontes utilizadas aqui são o jornal da Igreja Presbiteriana, ligado à "Missão ao Norte do Brasil", o Norte Evangélico e a revista missionária The Missionary Survey da Igreja Presbiteriana norte-americana (Presbyterian Church in the United States - PCUS, conhecida pelos historiadores brasileiros como a "Igreja do Sul") que enviava e mantinha missionários em Estados das regiões Norte e Nordeste do Brasil.
} 
vizinhas de Garanhuns-PE e Canhotinho-PE, onde entrevistei historiadores, intelectuais e pessoas comuns, fiéis ou não das igrejas presbiterianas daquelas cidades; também fui à Igreja Presbiteriana de Canhotinho algumas vezes, onde obtive o acesso às Atas Eclesiásticas guardadas no arquivo da igreja. Todos esses documentos e periódicos examinei pessoalmente e os fotografei visando à produção da minha tese doutoral.

Retomando a narrativa. A ossada de Né Vilella permaneceu no interior da igreja até o início de 1944, quando houve sua remoção para a sepultura ao lado da nave onde já descansavam George e Humphrey Butler. ${ }^{3}$ Naquele momento, ocorria a edificação de um mausoléu ${ }^{4}$ a partir daquela simples sepultura, objetivando homenagear a memória do Dr. Butler. ${ }^{5}$ Dessa forma, o período de 1915-1944 definiu o recorte temporal que balizou esse esforço em interpretar como ocorreu a construção da memória de George Butler, bem como, orientou a seleção das fontes históricas que utilizamos neste artigo.

A presença de sepulturas dentro e ao lado de uma igreja protestante no Brasil soa quase herético para um evangélico brasileiro do século XXI, e pode mesmo ter sofrido resistências de alguns pastores e fiéis protestantes do início e meados do século $\mathrm{XX}$, em razão de sua associação com práticas tradicionais do catolicismo. Assim, do meu espanto com os enterramentos de Né Vilella e George Butler abriram-se dois caminhos de análise. Primeiro, pareceram-me como uma via de acesso a outra cultura evangélica que tornou possível aqueles monumentos-fúnebres. Eles poderiam nos permitir compreender uma vivência da fé protestante específica de uma comunidade sertaneja no início do século XX.

Uma segunda via de análise relaciona-se ao processo de construção e reprodução de um monumento que se observa hoje como uma "fusão memorial" entre Né Vilella e George Butler, ambos os mais evocados na memória local e dos presbiterianos da região. (Embora também Humphrey Butler esteja ali sepultado, ele é quase apagado da memória, apenas é

\footnotetext{
3 Segundo Martins (2007, p. 93), "no pastorado do Rev. Luiz de França [1942-1945], de saudosa memória, e quando de modificações feitas no interior do templo, os ossos foram retirados de sob o púlpito e colocados na mesma campa em que repousam os restos mortais do Dr. Butler.

4 A crer na informação de Pelópidas Soares a construção do mausoléu foi obra da "Missão Evangélica Americana." (Diário de Pernambuco, 9 de março de 1950, suplemento "Pelos Municípios”).

5 O Jornal Norte Evangélico de $1^{\circ}$. de junho de 1944, p. 3, anunciou a inauguração daquele monumento da seguinte forma: "No dia 27 de maio de 1919, há 25 anos, portanto faleceu na cidade de Canhotinho, [...] George William Butler. A Igreja de Canhotinho, na data aniversária, inaugurou um novo mausoléu à memória do seu fundador...”
} 
lembrado como continuador do trabalho do pai, mas bem pouco se sabe dele; talvez por ter morrido apenas três anos após o falecimento do pai, não teve tempo de deixar uma marca própria de sua vida e serviço, nem legando uma memória sua à comunidade local). Nesse sentido, perante esse monumento-enigma (o Mausoléu do Dr. Butler que não é só dele), procurei atentar para as descrições do rito de (re)sepultamento da ossada de Né Vilella, tomando-o como um evento fundamental para a construção da memória do seu realizador, George Butler.

Embora o primeiro caminho de análise seja bastante interessante e frutífero, o objetivo deste artigo relaciona-se à segunda via, ou seja, buscar uma interpretação possível da construção da memória de George William Butler por meio do ritual de (re)sepultamento de Né Vilella, bem como, da produção de um lugar de memória por e para um grupo religioso atuante no interior pernambucano desde a virada do século XIX/XX até nossos dias.

Devemos a Pierre Nora (1993) uma reflexão sobre os lugares de memória. Seu objetivo é discutir a crescente produção contemporânea desses lugares e seu arrazoado é uma crítica à nossa obsessão pela memória. A raiz dessa vertigem memorial está no fato de que as sociedades modernas já não habitam na memória e, em meio à acelerada transformação de suas vidas, necessitam cristalizá-la em pontos de referência, esteios da memória fixos, como lugares, sejam eles museus, arquivos, monumentos, paisagens, datas, celebrações, livros etc., construídos como expressões concretas da memória coletiva (HALBWACHS, 2006).

Contrapondo os lugares de memória de Nora com os conflitos dos grupos sociais pela expressão pública de sua memória, tal qual a orientação de Pollak (1989), compreendi que a constituição de tais esteios da memória não são expressões espontâneas e neutras, mas imposições, produtos de lutas simbólicas pela memória social, na qual projetos de sociedade e de poder se afirmam em detrimento de outros que são ocultados, silenciados, mas permanecem latentes. "Por outro lado, essas memórias subterrâneas que prosseguem seu trabalho de subversão no silêncio e de maneira quase imperceptível afloram em momentos de crise em sobressaltos bruscos e exacerbados. A memória entra em disputa" (POLLAK, 1989, p. 4).

Tais perspectivas são fundamentais nesta análise, quando investigo um personagem caro a um grupo religioso, um personagem que foi monumentalizado em biografias, no seu "Mausoléu" e mesmo na patrimonialização dos edifícios que construiu na cidade de Canhotinho, especialmente o templo da Igreja 
Presbiteriana e do hospital. Esse "Hospital George William Butler" foi recentemente reformado e restaurado com investimento financeiro e simbólico da direção nacional da Igreja Presbiteriana do Brasil (IPB) 7 que, por meio de seus agentes, tomou para si a guarda e a promoção da memória do doutor Butler. Porém, antes da discussão sobre a monumentalização de sua biografia, passemos à análise do rito de (re)sepultamento.

\section{O Rito}

Figura 2: Fiéis reunidos no dia da inauguração do novo templo presbiteriano de Canhotinho-PE.

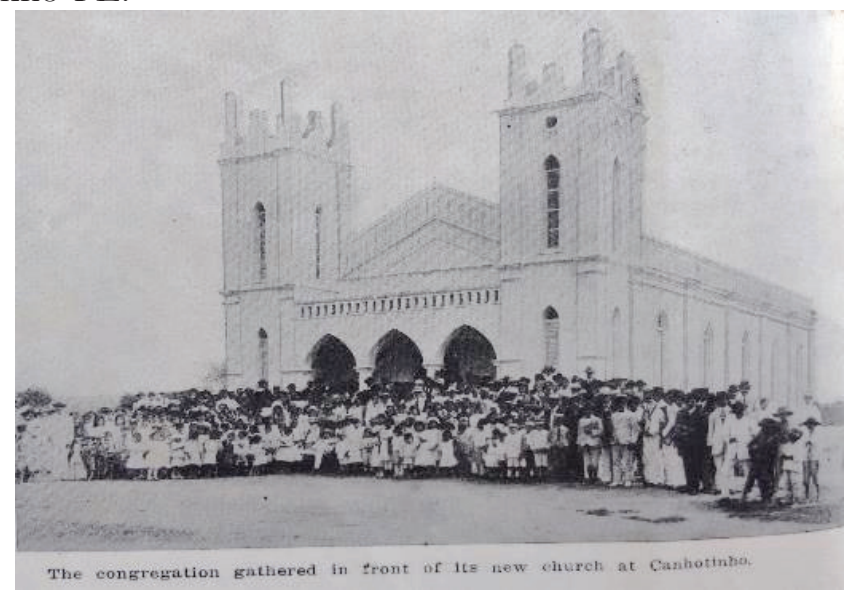

Fonte: The Missionary Survey, jan. 1916, p. 20.

Na manhã do dia 20 de julho de 1915 , cerca de 500 pessoas, entre mulheres, homens, idosos e muitas crianças se arranjaram à frente da igreja para caber numa fotografia (Figura 2), em memória da inauguração do

6 Assim está referido em "Decisões da Comissão Executiva do Supremo Concílio da Igreja Presbiteriana do Brasil 23 a 26 de março de 2015" que ordenava a liberação de recursos para a reforma e restauração do edifício. Não foram divulgados os valores: Jornal Brasil Presbiteriano, abril de 2015, p. 32. Disponível em: www.https://issuu.com/juninhonoiz/ docs/bp_especial_resolucoes_abril_2015_7265ba4a198fc6/1?e=3404691/32271910. Acesso em: 10 set. 2016.

7 O anúncio da reforma e restauração foi dado pelo presidente do Supremo Concílio da Igreja Presbiteriana do Brasil, em novembro de 2015, durante sua visita às igrejas da região, na ocasião das festividades dos 118 anos do presbiterianismo no agreste pernambucano e dos 115 anos da fundação das mais antigas instituições protestantes daquela região: as Igrejas Presbiterianas de Canhotinho, de Garanhuns e o Colégio XV de Novembro. 
novo templo presbiteriano de Canhotinho. Quatro anos depois, o fotógrafo daquela ocasião, o pastor da Igreja Presbiteriana do Recife, Antônio Almeida, relembrou o que aconteceu logo em seguida:

A multidão voltou imediatamente para dentro do templo, enquanto eu dobrava a machina alheia, punha-n'a cuidadosamente dentro do respectivo sacco com os chassis, desarmava e dobrava o tripé e ia guardar tudo no meu sempre lembrado quarto - o mesmo da outra vez. Quando voltei ao templo, que vi? Tinha acabado de perder o Discurso mais comovente que o Dr. Butler fez neste mundo, e fiquei estupefacto diante de seus effeitos! Elle acabava de depositar em uma urna feita no chão ao pé do pulpito os ossos de Né Villela - o homem que morrera por elle, recebendo a punhalada de um sicario que fôra assalariado para matá-lo em São Bento. Tinha narrado com tanta emoção o facto que uma das testemunhas oculares do acontecido desmaiara. E nesse momento, com voz entrecortada mas firme, cantava: "Cá soffremos afflicção,/Cá desgostos perto estão,/Mas lá no céu ha paz./Ob! Será alegre!/ Alegre, sim, alegre!/Ob! Será alegre!/Onde não ha separação!’. Ao meu lado caiu um companheiro com um ataque dos nervos, e a voz do Dr. continuava a se ouvir, entre os soluços de uns e os esforços de outros para o ajudar a cantar - sim continuava a mostrar quanto sua grande alma sabia apreciar a lealdade de um amigo que o foi até a morte! ${ }^{8}$

Essa narrativa do pastor Antônio Almeida surgiu nas páginas do jornal Norte Evangélico, um jornal presbiteriano sediado em Garanhuns e que possuía boa circulação nas igrejas do Norte/Nordeste. Ela se insere em uma edição inteiramente dedicada a homenagear George Butler, em 25 de junho de 1919, cerca de um mês após sua morte.

Se atentarmos para a narrativa, perceberemos que não foi o enterramento de uma ossada no interior da igreja que causou espanto ao pastor Antonio Almeida. O que o deixou "estupefacto" foi a catarse emocional que se seguiu ao discurso, sepultamento e cântico feitos e dirigidos por George Butler. Uma indicação de que a prática de enterrar uma ossada na nave de um templo protestante não seria um problema para esse pastor, e talvez também não seria estranho para a maioria dos participantes. $\mathrm{E}$ isso não só devido às heranças culturais católicas desses fiéis. O enterro de uma ossada embaixo do púlpito encontrava ressonância em outra prática ritual, essa bem protestante: o rito de "lançamento da pedra fundamental".

8 Norte Evangélico, 25 de junho de 1919, p. 3. 
A análise dos rituais praticados pelas primeiras igrejas protestantes parece um campo ainda bastante inexplorado pelos historiadores do protestantismo. A ausência de fontes mais descritivas dos ritos possivelmente colaborou para certa carência de estudos histórico-etnográficos das liturgias das primeiras comunidades protestantes. Todavia, penso que a explicação principal para esse pouco interesse esteja no sentimento de familiaridade que os pesquisadores (geralmente, pertencentes às igrejas protestantes) possuem sobre rituais como: Profissão de fé, Batismo, Santa Ceia, cultos dominicais etc. Seu próprio pertencimento religioso os levou a julgarem os ritos protestantes como desprovidos de interesse científico (por sua familiaridade), crendo (ainda que não manifestando essa crença) que tal interesse era reservado apenas para os ritos exóticos, como os das religiões afro-brasileiras. ${ }^{9}$

Ainda que muitas liturgias protestantes permaneçam sendo praticadas desde a inserção dos seus primeiros missionários no Brasil, há transformações importantes, sutis, não tanto nas formas externas, mas nas atitudes, sentimentos e significados que merecem uma investigação cuidadosa. Outros desses rituais das primeiras comunidades protestantes quase não existem mais e, quando nos defrontamos com eles nas fontes históricas, sentimos que guardam certa estranheza com relação às sensibilidades religiosas dos protestantes atuais.

É o caso do rito de lançamento da pedra fundamental na construção/ inauguração de um templo ou de outro edifício institucional, em que ocorriam uma série de atos de enterramento. O rito de lançamento da pedra fundamental tem, pela ocasião e pela forma, uma evidente relação com o que foi descrito na narrativa citada, como também os ritos fúnebres protestantes, pelo objeto (restos mortais) manipulado no rito em análise.

A cerimônia de lançamento da pedra fundamental, geralmente, ocorria durante uma inauguração de uma instituição protestante. No século XIX e início do XX, o ritual era uma espécie de apresentação da nova instituição àquela sociedade que a acolhia e cumpria a função de uma formalidade mais cívica do que religiosa. Em sua liturgia, Bíblias, estatutos e outros

\footnotetext{
O historiador Lyndon Santos (2015, p. 74) explica dessa forma a lacuna: "Um fator que contribuiu para esta ausência [de descrições etnográficas das liturgias protestantes] está no entendimento de que os evangélicos constituíam no Brasil uma subcultura religiosa, em contraponto à cultura hegemônica moldada pelo catolicismo e pelos cultos de origem africana". Em outras palavras, os protestantes, por não terem impacto na cultura brasileira mais ampla, não obtiveram a curiosidade dos historiadores das religiões para seus ritos, ao contrário das religiões de matriz africana ou mesmo do catolicismo popular.
} 
documentos administrativos e doutrinários da igreja, com jornais e outros impressos, eram colocados num cofre e enterrados no local onde ficaria o púlpito. $\mathrm{O}$ ato de enterrar Bíblias e outros documentos institucionais sob o púlpito sugeria uma identidade simbólica entre a pedra fundamental, marco físico de uma inauguração (ou o início de uma construção) e os fundamentos históricos, simbólicos e doutrinários de um grupo a serem (e que deveriam ser) enunciados daquele local.

O que ocorreu na inauguração do templo de Canhotinho é que George Butler secundarizou os significados cívicos e sobrecarregou na dimensão simbólico-religiosa do rito, produzindo novos significados destinados ao grupo de fiéis. A singularidade da opção pode-se atribuir ao fato de que não se tratava de uma "pedra fundamental" comum, mas do (re)sepultamento da ossada de um fiel visando consagrá-lo como um "mártir".

Essa feição de sepultamento de um mártir se sobrepôs aos sentidos de um "culto de dedicação", ou de lançamento de pedra fundamental e mudou completamente as características associadas com festividade, louvor, consagração de um templo que era, naquele momento, a maior obra de George Butler. ${ }^{10}$ Com efeito, ao lermos as descrições das fontes, percebemos que estamos diante de um rito fúnebre. O que ocorreu foi uma "transmutação ritual" na qual um conjunto ordenado de atos e gestos deslocaram uma celebração de inauguração para uma cerimônia de sepultamento, pois é como tal que se estruturou esse rito.

Para compreender melhor o ritual e relacioná-lo à produção de um monumento à obra e memória de George Butler, comparei diferentes narrativas registradas nas fontes históricas. Há, além da narrativa do pastor Antonio Almeida já citada, duas outras que, podemos dizer, surgiram quase no calor da hora (dias ou meses após o fato). Uma do presbítero Pedro Chaves, no Norte Evangélico de 10 de agosto de 1915, e outra do missionário George Henderlite, na revista The Missionary Survey, de janeiro de 1916.

É impressionante a narrativa do pastor Antônio Almeida, mas não podemos esquecer que se trata de uma rememoração e, ainda mais, algo que ele não assistiu por completo. A palavra "estupefacto" expressa a memória do seu choque ao se defrontar com os "effeitos" do discurso de George Butler,

10 Quatro anos após aquela inauguração, ainda se dizia que aquele era um "vasto Templo Evangelico, um dos maiores, sinão o maior do Norte do Brasil, a comportar igualmente, cremos, a maior Egreja do Presbyterio de Pernambuco!", uma região eclesiástica que ia de Alagoas ao Amazonas (jornal Puritano, 5 de junho de 1919, p. 8). 
após ele "depositar em uma urna feita no chão ao pé do pulpito os ossos de Né Villela”. Sua descrição da cena, mesmo após quatro anos, ainda guarda muito da catarse emocional que tomou conta daquele ambiente. A mesma irrupção emocional é percebida em outra narrativa mais contemporânea ao acontecimento, a do missionário George Henderlite:

O pai deste garoto com outros dois brasileiros que estiveram com o Dr. Butler em S. Bento, colocou a pedra no seu lugar de repouso em frente ao púlpito. Dr. Butler com suas mãos sobre a lápide com as deles - todos os quatro em pé juntos como eles devem ter feito junto ao corpo de seu companheiro morto na rua de S. Bento vinte anos atrás - falava com pesar por alguns minutos enquanto homens e mulheres irrompiam em grande pranto. ${ }^{11}$

Todavia, é o texto assinado por Pedro Chaves, presbítero da Igreja Presbiteriana de Garanhuns, que nos fornece detalhes sobre a liturgia da cerimônia. A narrativa foi publicada no Norte Evangélico apenas vinte dias após a inauguração sob o título "Consagração de um novo templo". Segundo a descrição do cronista, a cerimônia iniciou-se às 11 horas da manhã com o hino "Deus velará por ti, da inteligente educadora senhorita Cecilia Rodrigues". O sermão teve como tema "Christo a pedra fundamental, pedra de esquina e pedra angular" pregado pelo "reverendo doutor George Henderlite". Em seguida, o reverendo W. C. Porter dirigiu uma oração. Cantou-se o hino "O som do Evangelho" e o reverendo Benjamim Marinho procedeu "à leitura do seu importante folheto Recordações". Em seguida... ${ }^{12}$

...fazendo uso da palavra mais ou menos disse o rev. dr. Butler: Vou tirar um véu que há 17 annos se acha deante de vós. Certo dia achava-me com alguns irmãos, celebrando um culto na visinha cidade de S. Bento. Nesta ocasião um individuo penetrou no salão dizendo que lhe haviam mandado assassinar ao dr. Butler, mas que ele não era capaz de o fazer. A taes palavras demos mui pouca importancia. Mas, mais tarde, quando nos íamos retirando da cidade, um estafeta, que sahira correndo atraz de nós, tentou assassinar me vibrando uma punhalada no irmão Manoel Correia Vilella, que morreu incontinente,

11 "This boy's father with the other two Brazilians who were with Dr. Butler in S. Bento, laid the stone in its resting place in front of the pulpit. Dr. Butler with his hands on the tablet with theirs, - all four standing together as they must have done by the dead body of their comrade in the street of S. Bento twenty years ago - talked in subdued voice for a few minutes while men and women burst out in loud weeping" (The Missionary Survey, janeiro de 1916, p. 23; tradução do autor).

12 Toda a narrativa está no jornal Norte Evangélico de 10 de agosto de 1915, p. 1. 
dando, assim, a sua vida para me livrar da morte. Nunca pensei que além de Christo, que era Deus e homem, homem algum fosse capaz de morrer por mim. Crente algum deve jamais duvidar do amor do seu irmão. Em memoria desse saudoso irmão, fiz transportar para esta cidade, os seus ossos que se acham numa caixa enterrados aqui ao pé do púlpito. E, chamando os irmãos Mor. Joaquim Vitalino, Capm. Joel Vilella, Miguel Vilella e Francisco Peixoto, que se achavam presentes, disse: fomos nós cinco que assistimos ao triste facto. Convido estes irmãos para collocarmos aqui esta pedra, que contem os seguintes dizeres (começou a ler com palavras recortadas de soluços): Em memoria de Né Vilella, assassignado em S. Bento por causa do Evangelho. 1898. A scena foi comovedorissima, arrancando lagrimas aos circumstantes.

Quando observamos as partes, discursos e símbolos acionados no ritual narrado, fica claro que George Butler organiza a liturgia do culto de dedicação do templo com o objetivo de dar sentido à morte de Né Vilella e ao mesmo tempo reforçar os laços de solidariedade do grupo por meio do valor do sacrifício.

Há entre os estudiosos dos ritos fúnebres e da morte uma compreensão de que esses ritos derivam de um investimento simbólico-discursivo a fim de dar sentido a uma desordem no mundo efetivamente sentida pelos que compartilham uma perda. Enfim, faz-se do rito fúnebre uma oportunidade de reforço dos significados, das hierarquias e dos padrões de comportamento que se desejam fundantes para um grupo reunido em torno da memória de uma vida que não mais existe.

Daí que o rito seja sempre um acto social de exorcização da morte de restauração da ordem. É que também a sociedade se move por um desejo de eternidade. E, como ela se sente e quer ser imortal, é-lhe igualmente inaceitável que os seus membros - e, mais dramaticamente, aqueles que a encarnam e com quem ela se identifica - estejam destinados a desaparecer (CATROGA, 2010, p. 165).

O esforço de tornar imortal o grupo, especialmente aqueles que o encarnam, está implícito em todo ritual e nas palavras de George Butler: os cânticos usados em funerais, enfatizando o sofrimento que os fiéis devem passar na terra para obter o gozo celeste; um sermão expondo Cristo como "pedra fundamental" que foi "rejeitado", assassinado, para dar origem a uma nova "construção", uma nova fé; o discurso de Butler entrelaçando Cristo e Né Vilella como exemplos do amor entre os irmãos a ponto de dar sua 
vida pelo outro. O sepultamento dos restos de Né Vilella e a colocação de uma lápide sob o púlpito como a pedra fundamental daquele grupo de fiéis e sua nova fé tornaram visível ao grupo a representação da mensagem que se desejou transmitir com aquele rito: a necessidade do sacrifício pela "causa do Evangelho" - pelo grupo.

George Butler fala para seu grupo e fala em nome do grupo, com autoridade reconhecida pelos seus seguidores ${ }^{13}$ para estabelecer o consenso sobre essa morte - "vou tirar um véu que ha 17 annos se acha deante vós", especialmente na tentativa de desacreditar outras versões. É bem possível que, à época dessa inauguração, a memória desse assassinato ainda levantasse controvérsias.

Entrevistei um senhor em Garanhuns-PE, membro de uma das famílias mais antigas da cidade, e uma família católica, que me contou que Né Vilella andava pelas praças e feiras zombando da religião católica e, por causa disso, fora assassinado. É possível que essa tenha sido a versão e a memória que circulava entre as famílias católicas como forma de combater a versão protestante difundida por George Butler. Segundo a narrativa do médico-missionário, teria sido o vigário, Joaquim Alfredo da Costa Pereira, de São Bento, quem mandou matá-lo, mas como Né Vilella o defendeu, o sicário acabou apunhalando o homem errado.

Essa versão de George Butler, embora apareça desde o início nos jornais, ${ }^{14}$ em que ele denuncia o padre como mandante, não foi investigada no processo criminal que se instalou, indicando que as autoridades policiais e judiciárias ou não encontraram indícios suficientes para incriminar o padre ou acobertaram os indícios que o implicavam (CINTRA, 1986, p. 130-143). O certo é que a polícia e a justiça não vincularam o padre ao caso. Em julho de 1902, já louco e tendo sido considerado fora de suas faculdades mentais ${ }^{15}$ no momento do ato assassino, o réu, João Ribeiro da Silva, foi absolvido

13 George Butler possui um capital simbólico reconhecido pelo grupo, primeiro por ser seu pastor, segundo por ser visto como um "médico-humanitário". Portanto, alguém que era creditado como sabedor do que estava fazendo, tanto na perspectiva da doutrina religiosa quanto do ponto de vista médico-sanitário, para exumar uma ossada e transladá-la e, ao mesmo tempo, era um exemplo de abnegação e sacrifício "pelos pobres" e "pela causa do Evangelho", as últimas, características sempre ressaltadas pelos contemporâneos nas fontes históricas.

14 Jornal do Recife, 19 de fevereiro de 1898, p. 3; O Estandarte, 5 de março de 1898, p. 2.

15 "No dia 3 de julho de 1900, pelo ofício n". 900, a Casa de Detenção envia ao Hospício de Alienados o louco João Ribeiro da Silva” (CINTRA, PAIVA e FIRMINO, 1984, p. 109, 110). 
(CINTRA, 1986, p. 142) - outro elemento para desacreditar a versão do médico-missionário. Ele podia ter perdido a batalha no campo da justiça, mas precisava ganhar no campo da memória.

George Butler segue narrando detalhes que talvez fossem obscuros a muitos dos seus ouvintes naquela manhã. Mas o fundamental não está nos detalhes de uma tentativa de assassinato contra ele e que acabou vitimando Né Vilella (essa história, grosso modo, já era conhecida) e sim sobre como ela deve ser compreendida e deve balizar uma ética para a manutenção do grupo no futuro. Pois, como um Cristo, Né Vilella morreu "por mim", diz Butler, por conseguinte, "crente algum deve jamais duvidar do amor do seu irmão", ou seja, importa a coesão do grupo, o qual o missionário se propõe corporificar. Assim, o seu discurso produz o que Bourdieu chamou de "alquimia da representação" - o ato de enunciação "através do qual o representante constitui o grupo que o constitui" (1996a, p. 82, 83).

Ele recebe o direito de falar e agir em nome do grupo, de "se tomar pelo" grupo que ele encarna, de se identificar com a função à qual ele se entrega de "corpo e alma", dando assim um corpo biológico a um corpo constituído. Status est magistratus, "O Estado sou eu". Ou então, o que dá no mesmo, o mundo é minha representação (BOURDIEU, 1996a, p. 82, 83).

É nesse sentido que George Butler direciona seu discurso, diz ele: "Nunca pensei que além de Christo, que era Deus e homem, homem algum fosse capaz de morrer por mim. Crente algum deve jamais duvidar do amor do seu irmão". Em seguida, chamou à frente as quatro testemunhas que estavam com ele no atentado que vitimou Né Vilella: "Convido estes irmãos para collocarmos aqui esta pedra, que contem os seguintes dizeres (começou a ler com palavras recortadas de soluços): "Em memoria de Né Vilella, assassignado em S. Bento por causa do Evangelho. 1898”. Essas palavras operam a metonímia entre "morrer por ele", George Butler, e "morrer pelo Evangelho". 
Figura 3: Púlpito da Igreja de Canhotinho, com a placa em homenagem a Né Vilella.

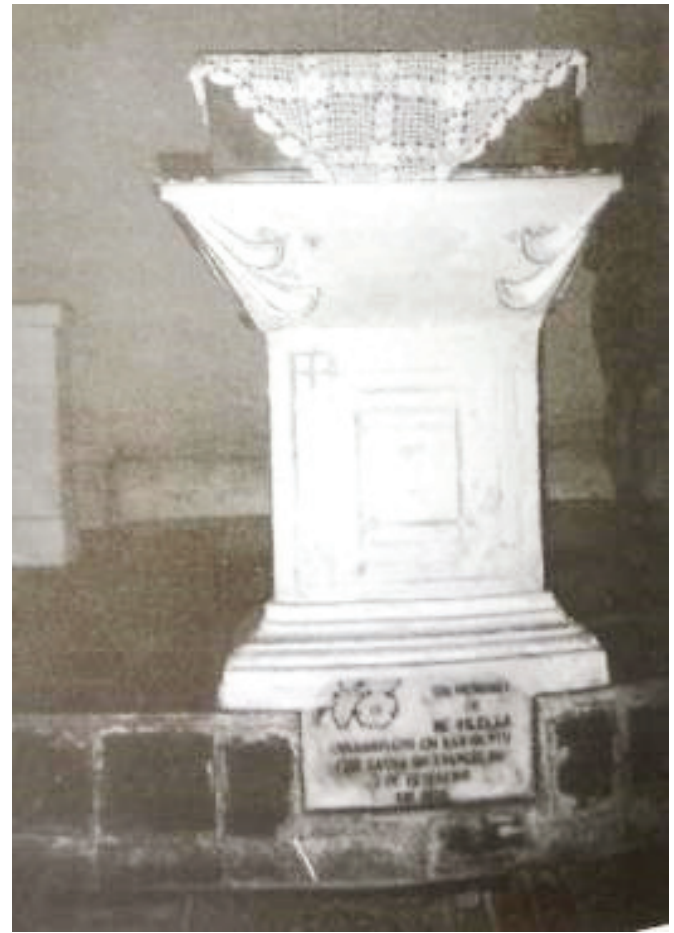

Fonte: SIQUEIRA, 1996.

O ritual e as palavras de George Butler fundem no imaginário da sua audiência duas mortes, a de Cristo e a de Né Vilella, ambos "por ele". Mas enquanto a morte de Cristo fundava a nova comunidade cristã, a morte de Né Vilella foi para salvar George Butler e a continuidade do grupo evangélico naquelas regiões de constantes ameaças. Né Vilella morreu "por ele", logo morreu "pelo Evangelho", morreu pelo grupo.

Nessa criação do "grupo feito homem", como diria Bourdieu (1996a, p. 83), o discurso performativo (acionando palavras e símbolos) do médico e missionário reelabora a memória numa versão que se impõe como legítima, a fim de constituir e fundar a existência daquele grupo sobre uma história de martírio a ser transmitida às gerações seguintes. E que se tornava a história de uma comunidade protestante sertaneja naquele momento em que se inaugurava seu suntuoso templo, como uma espécie de santuário à memória de "seu" mártir 
e, indiretamente, do construtor desse santuário-monumento, o responsável pela evocação dessa memória: George Butler, um homem feito símbolo.

Nesse ritual de novo sepultamento, cada ato e o discurso de George Butler reelaboram a memória da morte de Né Vilella a fim de fundar a existência do grupo sobre uma história de martírio. Uma memória que deveria ser constantemente comunicada às velhas e novas gerações pela presença constante e visível daquele memorial no interior da nave. Assim, não se tratava apenas de um templo sendo inaugurado, mas de um santuário-monumento à memória de um mártir sertanejo de uma comunidade protestante sertaneja, presente ali por seus restos mortais e uma lápide em sua homenagem; uma ausência sentida, mas uma presença imaginada que poderia ser sempre "revisitada". Por esse ato, George Butler transformou a Igreja Presbiteriana de Canhotinho em um memorial, um templo-monumento.

\section{A Memória}

Mobilizar o (re)sepultamento de Né Vilella no templo protestante foi um ato complexo em razão das sensibilidades envolvidas e dificuldades práticas. Demandou ter autorização da família, abrir uma sepultura, exumar os restos, acondicioná-los em uma urna apropriada, encomendar a fabricação da placa, reservar um espaço abaixo do púlpito durante a reforma do templo para receber a urna. Tudo isso sob perigo de ferir sensibilidades religiosas dos outros missionários norte-americanos, pastores brasileiros e mesmo dos demais adeptos da igreja que poderiam ver a presença de um morto no templo como referência a uma prática "Romana" ou como algo pouco afeito ao sentido higiênico da "civilização moderna".

Em tudo a execução desse ritual e dessa homenagem exigia uma ação bem planejada e um esforço cuja análise da sua motivação não pode deixar de considerar o lucro simbólico, apesar dos riscos que a cerimônia suscitaria, ao seu idealizador e executor. Mas no campo religioso, onde tudo se quer voltado para o transcendental, ao agente "é melhor aparecer como desinteressado do que como interesseiro, como generoso, altruísta, do que como egoísta" (BOURDIEU, 1996b, p. 154).

George Butler é alguém com o habitus do campo religioso, cujo sentido prático das lutas simbólicas e dos recursos disponíveis permitiu-lhe perceberse como um missionário da primeira geração e um dos últimos "pioneiros". Termo recorrente na historiografia eclesiástica protestante da época que conota não só a dimensão cronológica, como também a dimensão espacial do desbravamento. 
A inauguração daquele suntuoso templo em terras do binterland ${ }^{16}$ brasileiro era a coroação de seu pioneirismo, mas sua geração estava no fim, uma nova igreja nacional, com pastores brasileiros nos principais postos pedia passagem. Ele ainda era reverenciado como um "príncipe dos missionários", ${ }^{17}$ mas já não participava da liderança da instituição no Brasil e, nos Estados Unidos, era mais um médico-missionário entre outros espalhados por diversos continentes.

Diferente de outros pioneiros no Brasil e no mundo, George Butler não deixou diários da sua aventura missionária, não escreveu livros, não deixou sermões. Essas estratégias normalmente utilizadas por outros pioneiros para valorização de suas obras e perpetuação de seus nomes na história das missões, não foram as suas escolhas. ${ }^{18} \mathrm{Nem}$ mesmo seus filhos seguiram sua vocação missionária para promover sua memória.

Os edifícios que construiu (a igreja, a escola e o hospital) eram a sua obra de vida, o seu legado. Todavia, eram monumentos mudos sem um

16 Em interessante estudo sobre a ação da Missão Central do Brasil, uma missão da Igreja Presbiteriana do Norte dos Estados Unidos que se instalou no interior baiano no final do século XIX (1897), a historiadora Ester Fraga discorre sobre a tentativa de "implantar um projeto civilizador no binterland brasileiro através da organização de igrejas, escolas e hospitais" (NASCIMENTO, 2007, p. 79). As representações dos missionários protestantes sobre o hinterland brasileiro estudadas por Ester Fraga não destoam das representações utilizadas pelos missionários que atuavam no interior pernambucano: "no qual o binterland brasileiro era apresentado como um ambiente inóspito, com uma população ignorante, onde os representantes de Deus ofereciam não somente a salvação da alma como a restauração do intelecto e do corpo, através de suas igrejas, escolas e hospitais" (NASCIMENTO, 2007, p. 100, 101).

17 Em um folheto intitulado, "A Missionary who could do all things and was always content", o missionário George Henderlite denomina assim ao companheiro de missão, George Butler (1919, p. 1).

18 Os missionários norte-americanos da geração de George Butler, da segunda metade do século XIX, sabiam da importância do seu trabalho no Brasil: época de desbravamentos e aventuras. Consideravam-se continuadores do livro dos Atos dos Apóstolos e tão merecedores de terem seus nomes perpetuados na História da Igreja quanto os missionários pioneiros na África ou Ásia. Por isso, muitos deles escreveram diários (pouco íntimos) para serem publicados, autobiografias ou participaram da escrita de biografias e da história de sua denominação. A ambição de se perpetuar na história parece comum aos pioneiros e abraçada por seus aliados. Num artigo de 1917, o próprio George Butler foi colocado ao lado de grandes nomes da história das missões protestantes: "I may join his name to the ones of David Livingstone, Samuel Rutherford, James Gilmour and Stonewall Jackson...”. [Eu posso juntar seu nome aos de David Livingstone, Samuel Rutherford, James Gilmour e Stonewall Jackson...] In: CORTEZ, Nathanael. "A Faithful Missionary Doctor.” The Missionary Survey, fev. 1917, p. 132. 
texto que vinculasse perenemente seu nome àquele conjunto arquitetônico. A ocasião da inauguração do templo surgiu como a situação adequada para um memorial, mas evidentemente, conforme as regras do jogo no campo religioso, não poderia ser um monumento a si, isto soaria arrogância, orgulho... melhor seria se fosse um monumento àquele que "morreu por ele".

Certamente, não há somente cálculo, existem razões, quem sabe até maiores, de crença e emoção, que justifiquem a realização desse rito. George Butler certamente compartilhava das representações sobre o martírio, de amplo lastro histórico e doutrinário no cristianismo, associando-o à morte de Né Vilella e foi talvez o principal divulgador das representações do "martírio de Né Vilella" devido à suas convicções de fé, gratidão e afeto. Àquele que morreu passou a chamá-lo de amigo, sentia-se indigno de ter sido salvo por Né Vilella. ${ }^{19}$

Era a oportunidade de retribuir, eternizar a memória do amigo e envolvê-la em sacralidade. Porém, em tudo que George Butler discursou, jamais a vida de Né Vilella é narrada ou louvada, não é a sua vida que é lembrada, honrada, é a sua morte, e morte por Butler, pelo Evangelho. Por uma simbiose simbólica, a manutenção da vida de George Butler dá sentido à morte de Né Vilella e, reciprocamente, a morte de Né Vilella glorifica a vida de Butler, é ele a encarnação do Evangelho (e do grupo).

Ao trazer para dentro do novo templo de Canhotinho os restos mortais de Né Vilela, George Butler o transformou em mártir a ser celebrado pelas gerações futuras daquela comunidade protestante e, indiretamente, recebe também essa aura, envolvendo a si na memória do martírio. Seu esforço em erigir um monumento à memória de outro corrobora com a representação pública de sua identidade construída sob uma (auto)imagem de abnegação, altruísmo, humildade e, ao mesmo tempo, prolonga sua própria memória no futuro, mas evitando a aparência de autoglorificação.

Essa memória monumental vinculava-se intimamente a George Butler. Ele buscou compartilhar da aura do martírio. No seu discurso, acionando

\footnotetext{
19 Artigo de um desconhecido autor brasileiro, traduzido por Ruth B. See, narrando um encontro com George Butler no dia seguinte ao atentado: "Next day, I went to visit Dr. Butler and found him at family worship, which he regulary holds after breakfast. At the close of the service, I asked him: 'Doctor, why did they kill Vilella?' 'Because he was better than I and better than you', he replied calmly and emphatically" ["No dia seguinte, eu visitei o Dr. Butler e o encontrei no culto doméstico, o qual ele regularmente realizava depois do café. Depois de terminado o trabalho, eu perguntei a ele: 'Doutor, por que eles mataram Vilella?' 'Porque ele era melhor do que eu e melhor do que você', ele respondeu calma e enfaticamente".] In: The Missionary Survey, dez. 1916, p. 949.
} 
palavras e símbolos, o médico-missionário ao mesmo tempo em que sacraliza a memória de Né Vilella por seu ato de amor, projeta a memória de sua própria vida ao identificar a manutenção dela como a razão da existência daquele grupo evangélico: se Né Vilella morreu por ele, morreu pelo Evangelho.

Dessa forma, George Butler tornava o rito de (re)sepultamento daquele que morreu por ele, num ato inaugural de sacralização e de monumentalização da sua própria memória. Isso porque sua decisão de enterrar Né Vilella no interior da igreja - além de remeter a memória do grupo à vida do médicomissionário -, abria um precedente simbólico e prático para o seu próprio sepultamento ao lado do templo, como era a sua vontade manifesta, ${ }^{20}$ o que ocorreu quatro anos mais tarde, em 1919. Assim, George Butler passou a ter legitimidade para desfrutar de uma honra incomum no protestantismo brasileiro: o de ser lembrado pela presença constante de sua sepultura.

\section{A produção de um monumento}

No segundo semestre de 1918, George Butler esteve nos Estados Unidos. Foi, como de costume, apresentar palestras sobre o trabalho missionário no Brasil, mas acabou se envolvendo com a emergência da epidemia de gripe espanhola que atingia seu auge naquele semestre. Voltou ao Brasil em fevereiro de 1919 sentindo-se doente da gripe, mas deixou a esposa e as filhas nos Estados Unidos pois duas delas estavam com a gripe. Em Canhotinho, juntou-se ao filho, também médico, no trabalho do hospital. Ao final de maio, voltou a se sentir mal, vindo a óbito logo em seguida.

Na biografia que Dona Rena Butler faz sobre o marido, foi a gripe espanhola o fator desencadeador da sua morte: "Em seu retorno, o Doutor contraiu a gripe em Nova Iorque, e um coração enfraquecido causou sua morte". ${ }^{21}$ Porém, outra versão foi captada pelo jornalista Pelópidas Soares que, em de março de 1950, esteve em Canhotinho, publicando-a no Diário de Pernambuco em um artigo sobre o médico-missionário. Ele conta que depois de tomar uma coalhada, George Butler foi a cavalo visitar uma localidade para estudar "a possibilidade de uma fonte para abastecimento d'água encanada para a cidade". 22 Para o jornalista, esse comportamento gerou uma

\footnotetext{
$20 \quad$ Norte Evangélico, 25 de junho de 1919, p. 2.

21 "On his way back Dr. contracted flu in New York, and a weakened heart caused his death" (Dr. George Butler by Mrs. Butler, s/d, p. 2. Arquivo da Presbyterian Historical Society, RG 360, series III; tradução do autor).

22 Diário de Pernambuco, 9 de março de 1950, suplemento "Pelos Municípios".
} 
"congestão", hipótese que os biógrafos posteriores seguiram como causa da morte.

Sua morte ocorreu na tarde do dia 27 de maio e foi anunciada, no dia seguinte, no Jornal do Comércio de Recife. "Em Canhotinho, faleceu às 2 horas de hontem o conhecido medico dr. George Butler"; indicando como deveria ser lembrado: "A pobreza perde na sua pessoa um phylantropo, no sentido lato da palavra". ${ }^{23}$ No dia 28 ocorreu seu sepultamento, narrado também pelo Jornal do Comércio: ${ }^{24}$

Causou à toda população doloroso pesar, o passamento do humanitário medico operador dr. George William Butler, ocorrido às 15 horas do dia 27 e ocasionado por uma congestão hepática. Realizou-se o seu enterramento no local junto à igreja evangélica, às 14 horas do dia 28, comparecendo toda a população, vendo-se nos olhos da maior parte borbulharem lagrimas de sentido pesar. O extincto era natural dos E. U. da América do Norte, casado com mrs. Rina (sic) Mary Butler, havendo do seu consorcio 7 filhos naturaes do nosso paiz. Era um espirito caritativo e muito ira sofrer, com o seu desapparecimeno, a pobreza. Há cerca de 30 annos que residia nesta cidade onde grangeou a estima de todos; amava o solo brasileiro com devotamento, e em vida sempre manifestava o desejo de ser sepultado em nosso paiz. Era um homem de saúde e a morte levou-o quase de surpresa. O commercio em signal de sentimento cerrou as suas portas até a hora do enterro.

O "doloroso pesar" demonstrado pelo povo de Canhotinho com a perda do seu "humanitário medico" soma-se ao "devotamento" do morto ao "solo brasileiro", embora fosse um estrangeiro. São qualificações e representações de sua identidade que George Butler procurou construir, especialmente quando se instalou no interior pernambucano. O enterro ocorreu, entre a igreja e a escola, com a justificativa de atender ao seu manifesto "desejo de ser sepultado em nosso paiz".

23 Jornal do Comércio, 28 de maio de 1919, p. 2.

24 Jornal do Comércio, 11 de junho de 1919, p. 2. 
Figura 4: Túmulo de George Butler.

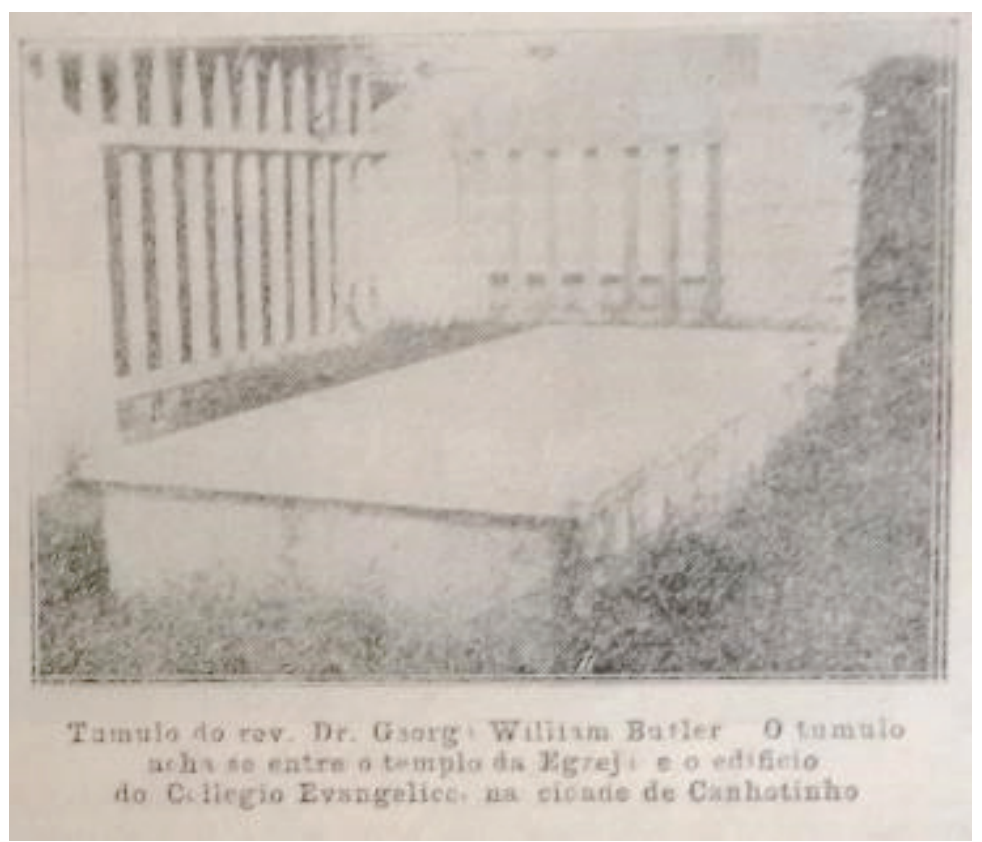

Fonte: Jornal Norte Evangélico, 11 de agosto de 1928, p. 4.

Na Figura 4, uma fotografia do túmulo de George Butler. Uma sepultura simples, não sendo possível identificar qualquer lápide ou inscrição, mas, conforme a edição do Norte Evangélico publicada em sua homenagem, "a egreja de Canhotinho mandou colocar no tumulo do pranteado" uma lápide com a seguinte inscrição: "Combati o bom combate, acabei a carreira, guardei a fé - II Tim. 4:7". ${ }^{25}$

Em 1944, a ata da Igreja Presbiteriana de Canhotinho ${ }^{26}$ de 5 de março registra: "Fica resolvido comemorar-se a passagem do vigesimo quinto aniversario do falecimento do saudoso missionario George William Butler, com a inauguração do mausoléu, ora em construção". Era o tempo do pastorado de Luiz Pereira de França (1942-1945) e as atas do início de

25 Norte Evangélico 25 de junho de 1919, p. 2.

26 Essas atas estão disponibilizadas aos pesquisadores no prédio do "Hospital do Dr. Butler" em Canhotinho, reformado e restaurado recentemente para funcionamento de uma unidade da Escola XV de Novembro, de Garanhuns. As fichas e as atas da Igreja Presbiteriana de Canhotinho, fotos e objetos do médico-missionário encontrei expostos em uma das salas destinada a um "Memorial Dr. Butler". 
1944 deixam claro que a igreja passava pela reconstrução do seu templo. Foi nessa oportunidade que, aproveitando da reforma no templo e construção do mausoléu, deu-se a retirada da ossada de Né Vilella do interior da igreja - sinal de que aquela presença se tornou incômoda -, mas mantendo a sua lápide sob o púlpito, mantendo-se a memória.

Assim se reuniam os restos de Né Vilella aos de George Butler. Com os seus restos, as duas memórias já simbolicamente justapostas, agora fundiam-se numa mesma matéria, numa mesma sepultura. Os dois sepultamentos na igreja produziam um único "lugar de memória", tornando-se um lugar de referência da história do protestantismo no nordeste brasileiro. Ainda hoje, o local é muito visitado por pastores, seminaristas, fiéis em geral (mesmo por evangélicos de outras denominações), pesquisadores da história do protestantismo e sempre (re)apresentado pela instituição e seus agentes por meio de livros de história, fotos divulgadas em páginas eletrônicas (vide nota 1) etc., relembrando a história que cruzou a vida e a memória de ambos os personagens.

Os dois sepultamentos fundiram-se num único monumento constituído e mantido pelos atuais grupos dirigentes da igreja presbiteriana como símbolo de uma identidade que se pretende inalterada no tempo. Os materiais do passado não são o conjunto do que existiu, mas uma sobrevivência do passado, como diria Le Goff, produto de "uma escolha efetuada quer pelas forças que operam no desenvolvimento temporal do mundo e da humanidade, quer pelos se dedicam à ciência do passado e do tempo que passa, os historiadores". O monumento compartilha desse caráter seletivo e é produzido para "evocar o passado, perpetuar a recordação" (LE GOFF, 2013, p. 485, 486).

\section{Considerações finais}

Nesse sentido, a monumentalização da vida de George Butler associando-a a morte de Né Vilella - reforça as características virtuosas que a tradição do grupo tornou consensuais e representativas de si próprio, ocultando as memórias conflituosas, ou nada lisonjeiras desse passado. De maneira que as destacadas virtudes de George Butler como humildade, altruísmo e abnegação sacrificial, rememoradas pelo monumento, não são somente dele mas também do grupo em que ele se insere - o dos agentes de evangelização protestante.

Uma autoglorificação da identidade, mas também um projeto de ação para o presente e o futuro. Sendo um monumento à memória de 
George Butler, seu Mausoléu construído em 1944 e ainda hoje divulgado, reproduzido e valorizado como um esteio fixo da memória, atende ao anseio de autoidentificação dos poderes eclesiásticos atuais com seus heróis do passado. Evidencia-se, por meio dessa memória, um perfil ideal do agente eclesiástico nos sertões do Brasil: um servidor caritativo do povo e dos pobres, jamais um crítico das estruturas que os mantêm na pobreza, apenas silente ou conivente com as mesmas. Esse modelo missionário e eclesiástico é transmitido para o grupo de fiéis e para as futuras gerações de agentes da instituição ${ }^{27}$ como um exemplo a ser seguido.

Dessa forma, a simbiose memorial entre George Butler e Né Vilella produziu um monumento com claro sentido normativo para aquele grupo religioso protestante: o da necessidade de serviço altruístico, sacrificial e abnegado naquelas regiões dos sertões nordestinos, se preciso for, até o martírio, pela "causa de Cristo".

\section{Referências}

BOURDIEU, Pierre. Economia das trocas linguísticas. São Paulo: EDUSP, 1996a.

. É possível um ato desinteressado? In: BOURDIEU, Pierre. Razões práticas: sobre a teoria da ação. Campinas, SP: Papirus, 1996b, 137-156.

BURKE, Peter. A Invenção da Biografia e o Individualismo Renascentista. Estudos Históricos. Rio de Janeiro: Fundação Getúlio Vargas, n. 19, 1997, p. 1-14.

CARTROGA, Fernando. O culto dos mortos como uma poética da ausência. ArtCultura, Uberlândia, v. 12, n. 20, jan./jun. 2010, p. 163-182.

CINTRA, Ivete de M.; PAIVA, Adalberto; FIRMINO, Pe. João. São Bento do Una: formação histórica. Recife: Centro de Estudos de História Municipal FIAM, 1984.

CINTRA, Sebastião Soares. Inocentes e Culpados no Tribunal do Juri de São Bento. Coleção Tempo Municipal-8. Recife: Centro de Estudos de História Municipal, 1986.

DARNTON, Robert. O Grande Massacre de Gatos: e outros episódios da história cultural francesa. Tradução de Sonia Couto. Rio de Janeiro: Graal, 1986.

FERREIRA, Júlio Andrade. História da Igreja Presbiteriana do Brasil. São Paulo: Casa Editora Presbiteriana, 1959.

HALBWACHS, Maurice. A Memória Coletiva. São Paulo: Centauro, 2006.

Principalmente por meio da divulgação das biografias de George Butler, notadamente a de Édijéce Martins A Bíblia e o Bisturi, na instituição de formação desses novos agentes eclesiásticos destinados às igrejas presbiterianas de todo o Nordeste, isto é, O Seminário Presbiteriano do Norte (SPN) em Recife-PE. 
IGREJA PRESBITERIANA DO BRASIL. Igreja Presbiteriana, 150 anos evangelizando o Brasil. Disponível em: https://www.youtube.com/watch?v=bjmbdP9_z3o. Acesso em: 6 fev. 2016.

LE GOFF, Jacques. História e Memória. Tradução de Bernardo Leitão [et al.], 7. ed. Campinas, SP: Editora da Unicamp, 2013.

LESSA, Vicente Themudo. Annaes da $1^{\text {a }}$ Egreja Presbyteriana de São Paulo (1863-1903): subsídios para a história do presbyterianismo brasileiro. São Paulo: S.C.P., 1938.

MARTINS. Edijéce. A Bíblia e o Bisturi: biografia do Dr. George William Butler, 2. ed. São Paulo: Cultura Cristã, 2007.

NASCIMENTO, Ester Fraga Vilas-Bôas. Educar, Curar, Salvar: uma ilha de civilização no Brasil Tropical. Maceió: EDUFAL, 2007.

NORA, Pierre. Entre Memória e História: a problemática dos lugares. Projeto História. São Paulo: PUC, n. 10, dez. 1993, p. 7-28.

O AGRESTE Presbiteriano. Disponível em: < https://oagrestepresbiteriano.blogspot. com/2013/06/historia-da-igreja-presbiteriana- do.html>. Acesso em: 10 jul. 2015). (N do Editor: A obra não tem nome do autor)

POLLAK, Michael. Memória, esquecimento, silêncio. Estudos Históricos. Rio de Janeiro: Fundação Getúlio Vargas, v. 2, n. 3, 1989, p. 3-15.

RODRIGUES, Meyves e CLEMENTINO, Emanuel. O Padre Cícero Protestante. Recife: Ed. dos Autores, 2015.

SANTOS, Lyndon de Araújo. Identidades Evangélicas no Brasil: um ensaio histórico cultural dos seus ritos e subjetividades. In: PORTELA, Camila et al. (Orgs.). Leituras sobre religião: cultura, política e identidade. São Luís: EDUFMA, 2015.

SIQUEIRA, Célio. Embaixador e Forasteiro: biografia do Rev. Cícero Siqueira. São Paulo: Cultura Cristã, 1996.

SOARES, Caleb. 150 anos de paixão missionária. São Paulo: Cultura Cristã, 2010.

SOUZA, José Roberto de. Um médico muito amado no agreste pernambucano. Revista Olhar Cristão, mar./abr. 2015, p. 26-27. Disponível em: <https://www.editoraculturacrista.com.br/ loja?term=biografia\&searchfield=_all\&tags=*> Acesso em 9 mar. 2018.

VIEIRA, David Gueiros. A Historical Study of the missionary work of Dr. George W. Butler and ananalysis of his influence on Brazil. Dissertação (História). University of Richmond, Virginia, 1960.

Submetido em: 18-10-2017

Aceito em: 28-11-2018 